\title{
Spectrophotometric determination of $\beta$-blocker drugs by oxidation with bromate-bromide mixture and its analytical application to pharmaceutical preparations
}

\author{
Akram M. El-Didamony* and Eman A.H. Erfan \\ Department of Chemistry, Faculty of Science, Zagazig University, Zagazig, Egypt
}

\begin{abstract}
Three visible spectrophotometric methods (A-C) were developed for the analysis of some $\beta$-blocker drugs, namely atenolol (ATE) and timolol (TIM) based on their reactivity with bromine, generated in situ by the action of hydrochloric acid on bromate-bromide mixture. The determination of residual bromine is based on its ability to bleach the indigo carmine dye and measuring the absorbance at $610 \mathrm{~nm}(\operatorname{method} \mathrm{A})$. Methods B and C involve treating the unreacted bromine with a measured excess of iron (II), the remaining iron (II) is complexed with 1,10-phenanthroline (method B) or with 2,2'-bipyridyl (method C) and measuring the increase in absorbance at 510 and $522 \mathrm{~nm}$, respectively. In all the methods, the amount of bromine reacted corresponding to the drug content. Regression analysis of Beer's plot showed good correlation in the concentration ranges of $0.4-16.4,0.8-10.4$ and $0.4-12.8 \mu \mathrm{g} / \mathrm{ml}$ using methods A-C, respectively, for ATE and 14-38, 12-32 and $14-38 \mu \mathrm{g} / \mathrm{ml} \mathrm{us}-$ ing methods $\mathrm{A}-\mathrm{C}$, respectively, for TIM. The optimum reaction conditions and other analytical parameters are evaluated. No interference was observed from the additives and the applicability of the methods was tested by analyzing the pharmaceutical preparations containing the investigated drugs. Statistical comparison of the results with those of official methods shows excellent agreement and indicates no significant difference in precision.
\end{abstract}

Keywords: Spectrophotometry, redox reactions, bromate-bromide mixture, $\beta$-blocker drugs, pharmaceutical preparations

\section{Introduction}

Beta blockers are a common class of prescription drugs that counteract the stimulatory effects of adrenaline (epinephrine) on what are called the beta receptors. These receptors are found in many tissues of the body including the nervous system and heart. When beta receptors are stimulated, the heart beats faster and harder and the blood vessels constrict, resulting in an elevation of blood pressure. Atenolol and timolol belong to $\beta$-blockers that block activity of $\beta$-adrenergic receptors and are of wide spectrum of pharmacological action; used in the treatment of ischemic heart disease, coronary failure, or as illegal doping agents $[16,17,40]$.

Atenolol, 4-(2-hydroxy-3-isopropylaminopropoxy) phenyl acetamide (Scheme 1), which in therapeutics is known as a beta-blocker and is widely used in the management of hypertension, angina pectoris, cardiac dysrhythmias and myocardial infarction [35]. The drug is official in the Indian pharmacopoeia

\footnotetext{
*Corresponding author. E-mail: ak_eldidamony@yahoo.com.
} 
<smiles>CC(C)NCC(O)COc1ccc(CC(N)=O)cc1</smiles>

Atenolol<smiles>CC(C)(C)NCC(O)COc1nsnc1N1CCOCC1</smiles>

Timolol maleate

Scheme 1. Chemical structure of the investigated drugs.

[32], which describes a UV-spectrophotometric method for its assay in tablets. The drug is also official in the British pharmacopoeia [9], which describes high-performance liquid chromatographic which is twostage processes. A wide range of chromatographic techniques, such as HPLC [13,14,39,45], HPTLC [3], LC [12,38]. Other techniques include voltammetric [20,21,36], electrophoresis [4,29,37], chemiluminescence [23,28], kinetic spectrophotometry [2], UV-spectrophotometry $[8,19,24,44]$ and visible spectrophotometric methods $[1,7,18,27,42]$.

Timolol maleate, (-)-(S)-1-tert-butylamino-3-(4-morpholino-1,2,5-thiadiazol-3-yloxy)-2-propanol (Scheme 1), is used as an antihypertensive and an antiglucoma agent. Literature survey revealed that very few methods have been reported for the determination of TIM in pharmaceutical preparations and there is, at present, only one visible spectrophotometric method for quantification of TIM [6]. Here, also, derivative UV [15], HPLC [22], HPTLC [25,26], LC [30,34], voltammetry [5,32,43] and potentiometry [11]. Timolol is officially recognized in the USP [41] and BP [10]. The method of analysis for the bulk drug was non-aqueous titration detecting the end point potentiometrically. The above-mentioned techniques, of course, are sensitive enough but are expensive. Spectrophotometry is the technique of choice even today due to its inherent simplicity. It is frequently used in our laboratories for the routine analytical work. Therefore, the aim of the present work was directed to develop simple, sensitive and accurate spectrophotometric methods for the analysis of two $\beta$-blocker drugs, namely atenolol and timolol maleate by oxidation with bromine, generated in situ by the action of hydrochloric acid on bromate-bromide mixture.

\section{Experimental section}

\subsection{Instruments}

All the absorbance spectral measurements were made using spectroscan $80 \mathrm{D}$ double-beam UV/Visible spectrophotometer (Biotech Engineering Ltd., UK), with wavelength range 190-1100 nm, spectral bandwidth $2.0 \mathrm{~nm}$, with $10 \mathrm{~mm}$ matched quartz cells. An Orion Research Model $601 \mathrm{~A} /$ digital 
analyzer, $\mathrm{pH}$-meter with a combined saturated calomel glass electrode was used for $\mathrm{pH}$ measurements.

\subsection{Reagents and materials}

All reagents and chemicals used were of analytical or pharmaceutical grade and all solutions were prepared fresh daily.

\subsubsection{Standard solution of pure drugs}

Pharmaceutical grade atenolol and timolol maleate were received from Egyptian Pharmaceutical Industries (EIPICO), 10th of Ramadan City, Egypt; which were reported to be $99.8 \%$ purity, as gift and were used as received. A stock standard solutions containing $10 \mathrm{mg}$ of ATE and $50 \mathrm{mg}$ of TIM were prepared by dissolving appropriate weight of pure drugs in distilled water and made up to the mark in a $100 \mathrm{ml}$ calibrated flask for obtaining working concentration $(100 \mu \mathrm{g} / \mathrm{ml})$ for ATE and $(500 \mu \mathrm{g} / \mathrm{ml})$ for TIM.

\subsubsection{Bromate-bromide mixture}

A stock standard solution of bromate-bromide solution equivalent to $100 \mu \mathrm{g} / \mathrm{ml} \mathrm{KBrO}_{3}$ and 10 -fold excess of $\mathrm{KBr}$ was prepared by dissolving accurately weighed $10 \mathrm{mg}$ of $\mathrm{KBrO}_{3}$ and $100 \mathrm{mg}$ of $\mathrm{KBr}$ in distilled water and diluting to $100 \mathrm{ml}$ in a calibrated flask.

\subsubsection{Indigo carmine}

A stock solution of $5 \times 10^{-4} \mathrm{M}$ indigo carmine (IC) (Aldrich) (2,2'-bis(2,3-dihydro-3-oxoindolyliden), Indigotin), $\left(\mathrm{C}_{16} \mathrm{H}_{10} \mathrm{~N}_{2} \mathrm{O}_{2}\right.$, M.Wt. $\left.262.27 \mathrm{~g} / \mathrm{mol}\right)$ was prepared by dissolving $23.31 \mathrm{mg}$ of dye $(99 \% \mathrm{pu}-$ rity) in distilled water and diluting to $100 \mathrm{ml}$ in a calibrated flask.

\subsubsection{Ferrous ammonium sulfate}

A stock solution of ferrous ammonium sulfate with concentration of $5 \times 10^{-3} \mathrm{M}$ was freshly prepared by dissolving $1960 \mathrm{mg}$ from $\left(\mathrm{NH}_{4}\right)_{2} \mathrm{Fe}\left(\mathrm{SO}_{4}\right)_{2} \cdot 6 \mathrm{H}_{2} \mathrm{O}$ in $20 \mathrm{ml}$ distilled water containing $1.0 \mathrm{ml}$ of $1.0 \mathrm{M}$ $\mathrm{H}_{2} \mathrm{SO}_{4}$ and then diluted to $100 \mathrm{ml}$ in a calibrated flask with distilled water.

\subsubsection{1,10-phenanthroline}

A stock solution of $0.2 \%(\mathrm{w} / \mathrm{v})$ of 1,10-phenanthroline monohydrate (Sigma Chemical Company, St. Louis, MO, USA), was made up by dissolving the solid in $1.0 \mathrm{ml}$ of $2.0 \mathrm{M} \mathrm{HCl}$ and then diluted to $100 \mathrm{ml}$ in a calibrated flask with distilled water.

\subsubsection{2,2'-bipyridyl}

A stock solution of $0.5 \%$ w/v of 2,2'-bipyridyl (Sigma Chemical Company, St. Louis, MO, USA), was made up by dissolving the solid in $1.0 \mathrm{ml}$ of $2.0 \mathrm{M} \mathrm{HCl}$ and then diluted to $100 \mathrm{ml}$ in a calibrated flask with distilled water.

\subsubsection{Ammonia solution}

A stock solution of $1: 1 \mathrm{v} / \mathrm{v}$ ammonia was prepared by diluting $50 \mathrm{ml}$ of concentrated ammonia with $50 \mathrm{ml}$ of distilled water in $100 \mathrm{ml}$ calibrated flask.

\subsubsection{Hydrochloric acid}

A stock solution of $2.0 \mathrm{M} \mathrm{HCl}$ was prepared by diluting $41.8 \mathrm{ml}$ of concentrated acid (sp. gr. 1.18, $37 \%$ ) to $250 \mathrm{ml}$ in a calibrated flask with distilled water. 


\subsection{Recommended procedures and calibration curves}

\subsubsection{Method A: Using indigo carmine}

Aliquot volumes of ATE covering the working concentration range $(0.4-16.4 \mu \mathrm{g} / \mathrm{ml})$ and $(12-38 \mu \mathrm{g} / \mathrm{ml}$ of TIM) solution were transferred into separate $25 \mathrm{ml}$ volumetric flasks by means of a micro burette. Then, $1.0 \mathrm{ml}$ of $2.0 \mathrm{M} \mathrm{HCl}$ was added; followed by 1.3 and $2.0 \mathrm{ml}$ of bromate-bromide reagent $(0.01 \%$ w/v $\mathrm{KBrO}_{3}$ ) for ATE and TIM drugs, respectively. The flasks were mixed well and set aside for 10 and $25 \mathrm{~min}$ for ATE and TIM, respectively, with occasional shaking. Finally, 6.0 and $4.0 \mathrm{ml}$ of $5 \times 10^{-4} \mathrm{M}$ IC dye for ATE and TIM was added; diluted to the mark with water and mixed well. The absorbance of each solution was measured at $610 \mathrm{~nm}$ against a reagent blank after $5 \mathrm{~min}$. The concentration of the unknown was read from the calibration graph or calculated using the regression equation obtained by using the Beer's law.

\subsubsection{Methods B and C: Using 1,10-phenanthroline or 2,2'-bipyridyl}

The oxidation of ATE and TIM performed by adding (0.8-10.4 and $0.4-12.8 \mu \mathrm{g} / \mathrm{ml}$ of ATE) and (1238 and $14-38 \mu \mathrm{g} / \mathrm{ml}$ of TIM) using methods $B$ and C, respectively, followed by addition of 1.0 and $2.0 \mathrm{ml}$ of bromate-bromide reagent $\left(0.01 \% \mathrm{w} / \mathrm{v} \mathrm{KBrO}_{3}\right)$ for ATE and TIM drugs respectively, for both methods and after acidification with $1.0 \mathrm{ml}$ of $2.0 \mathrm{M} \mathrm{HCl}$. The flasks were mixed well and allowed to stand for 10 and $25 \mathrm{~min}$ at room temperature for ATE and TIM, respectively. Then, $0.7 \mathrm{ml}$ of $5 \times 10^{-3} \mathrm{M}$ FAS was added for methods B and C, and then set aside for $10 \mathrm{~min}$ with occasional shaking. Finally, 1.0 and $1.4 \mathrm{ml}$ of $0.2 \% \mathrm{w} / \mathrm{v}$ of 1,10-phenanthroline were added for ATE, and TIM respectively, or 1.4 and $1.8 \mathrm{ml}$ of $0.5 \% \mathrm{w} / \mathrm{v}$ of 2,2'-bipyridyl were added for ATE and TIM, respectively. For accelerating the formation of the red iron (II)-phen or iron (II)-2,2'-bipyridyl complex, $1.0 \mathrm{ml}$ of $(1: 1 \mathrm{v} / \mathrm{v})$ ammonia solution was added for each drug for both methods B and C. Diluted to the mark with distilled water; mixed well and then measuring absorbance at 510,522 nm against reagent blank for methods B and C, respectively. The concentration of unknown was read from calibration graphs or calculated using the regression equation obtained by using Beer's law.

\subsubsection{Assay of pharmaceutical formulations}

Tablets containing the drugs were obtained from the local market. Atenolol pharmaceutical preparations were tenormin tablets, $50 \mathrm{mg} / \mathrm{tab}$ (AstraZeneca, Egypt) and atelol tablets, $50 \mathrm{mg} / \mathrm{tab}$ (Pharco, Egypt). The TIM pharmaceutical preparations were cusimolol eye drops, Sterile Ophthalmic solution, $5 \mathrm{mg} / \mathrm{ml}$ (Rameda, 10th of Ramadan City, Egypt). The procedure was continued as described under procedures for calibration curves.

\subsubsection{Procedure for the tablets}

For atenolol tablets. In order to demonstrate the applicability of the proposed methods for the assay of pure ATE and TIM in commercial pharmaceutical formulations in the presence of additives and excipients, such as talc, lactose, fructose, calcium hydrogen phosphate, magnesium stearate and starch. At least ten tablets of tenormin tablets, $50 \mathrm{mg} / \mathrm{tab}$ or atelol tablets, $50 \mathrm{mg} / \mathrm{tab}$ were powdered and a quantity of the powder equivalent to $10 \mathrm{mg}$ ATE was extracted by shaking with $10 \mathrm{ml}$ distilled water. The extracts were filtered into a $100 \mathrm{ml}$ calibrated flask and then diluted to the mark. The assay for ATE content was completed as described under procedures for calibration curves.

For timolol eye drops. For cusimolol eye drops (Sterile ophthalmic solution $5 \mathrm{mg} / \mathrm{ml}$ ), of TIM pharmaceutical preparations, an accurate measured volume equivalent to $50 \mathrm{mg}$ of drug was transferred into 
a $100 \mathrm{ml}$ calibrated flask; diluted to the mark with distilled water. The assay for TIM content was completed as described under procedures for calibration curves.

\section{Results and discussion}

Preliminary experiments revealed that atenolol and timolol maleate drugs are prone to both oxidation and substitution reaction by bromine generated, in situ by the action of acid on a bromate-bromide mixture. The unreacted oxidant was determination by three different reaction pathways (Scheme 2).

\subsection{Optimization of the reaction conditions}

The optimum conditions for color development for each method and stability of the complex were established by varying the parameters one at a time, keeping the others fixed and observing the effect produced on the absorbance of the colored species.

\subsection{Effect of mixing time}

The effect of mixing time required to complete oxidation of ATE and TIM drugs and for reducing the excess oxidant was studied by measuring the absorbance of sample solution against blank solution

Drugs $+\mathrm{BrO}_{3}^{-}+\mathrm{Br}^{-}+\mathrm{H}^{+} \longrightarrow$ Oxidation product of drugs + Unreacted $\mathrm{Br}_{2}$

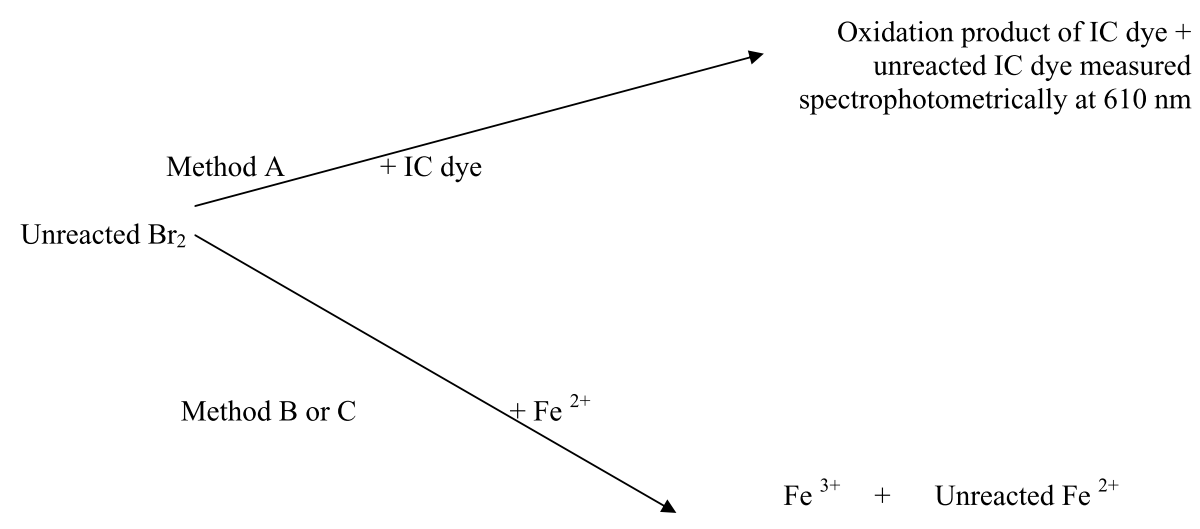

Or with:

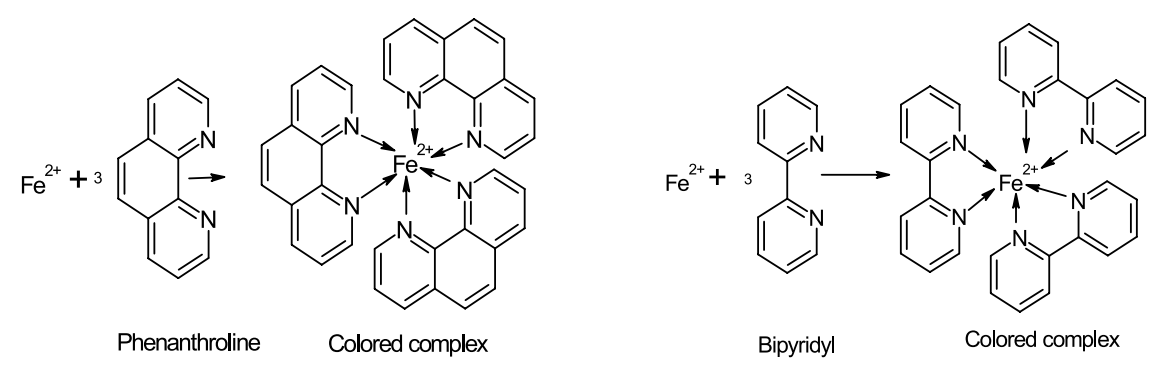

Scheme 2. Possible reaction pathway of methods A-C. 
prepared similarly at various time intervals $5-30 \mathrm{~min}$, at 610,510 and $522 \mathrm{~nm}$ for methods A, B and C, respectively. It was found that the contact times which gave constant and reproducible absorbance values at $10 \mathrm{~min}$ at room temperature $\left(25 \pm 2{ }^{\circ} \mathrm{C}\right)$ for ATE and $25 \mathrm{~min}$ for TIM for methods A-C. The time required for complete oxidation of ATE and TIM is not critical and any delay up to $30 \mathrm{~min}$ in the determination of unreacted bromine had no effect on the absorbance. A 5.0 min standing time was found necessary for the complete bleaching of the dye color by the residual bromine for method A and $10 \mathrm{~min}$ standing time was found necessary for complete reduction of residual bromine by ferrous ammonium sulfate for both methods B and C.

\subsection{Selection of acid type and acid concentration}

The reactions were tested in $\mathrm{HCl}, \mathrm{H}_{2} \mathrm{SO}_{4}, \mathrm{HNO}_{3}$ and $\mathrm{CH}_{3} \mathrm{COOH}$ solutions. The results indicate that the reaction is suitable in hydrochloric acid medium. A $2.0 \mathrm{M}$ hydrochloric acid was found to be adequate for the oxidation of the drugs as well as the complex formation reactions. The variation in $\mathrm{HCl}$ concentration indicated that constant absorbance was obtained with $0.2-2.0 \mathrm{ml}$ of $2.0 \mathrm{M} \mathrm{HCl}$ for ATE and TIM; so subsequent studies were performed with $1.0 \mathrm{ml}$ of $2.0 \mathrm{M} \mathrm{HCl}$ for each drug for methods A-C.

\subsection{Sequence of addition}

The sequence of addition of bromate-bromide mixture, drug solution and $\mathrm{HCl}$ were studied via the formation of the colored complexes. There was no appreciable change in the absorbance of oxidation product when the sequence of these reactants was altered.

\subsection{Method A: Using indigo carmine}

The proposed spectrophotometric method is indirect and is based on the determination of the residual bromine (in situ generated) after allowing the reaction between ATE or TIM and a measured amount of bromine to be complete. The bromine was determined by reacting it with a fixed amount of indigo carmine dye (Fig. 1). The method makes use of bleaching action of bromine on the dye, the discoloration being caused by the oxidative destruction of the dye.

In the proposed spectrophotometric method using indigo carmine, different amounts of ATE or TIM were treated with an excess of bromate-bromide reagent in hydrochloric acid medium and the unreacted bromine was determined by treating with a fixed amount of the dye and measuring the increase in absorbance at $610 \mathrm{~nm}$. The increase in absorbance was found to be directly proportional to the drugs concentration.

Preliminary experiments were performed to fix the upper limits of the dye that could be determined spectrophotometrically, and these were found to be 6.0 and $4.0 \mathrm{ml}$ of $5 \times 10^{-4} \mathrm{M} \mathrm{IC}$, for ATE and TIM, respectively. This color was completely and irreversibly bleached by $(1.3$ and $2.0 \mathrm{ml}$ of $0.01 \%$ $\mathrm{w} / \mathrm{v} \mathrm{KBrO}_{3}$ ) in the presence of a large excess of bromide (Fig. 2). Hence, different amounts of ATE and TIM were reacted with $\left(1.3\right.$ and $2.0 \mathrm{ml}$ of bromate-bromide reagent, $\left.0.01 \% \mathrm{w} / \mathrm{v} \mathrm{KBrO}_{3}\right)$ and after the oxidation-bromination reaction was judged to be complete, the surplus bromine was determined by treating with 6.0 and $4.0 \mathrm{ml}$ of $5 \times 10^{-4} \mathrm{M}$ of IC dye solution and measuring the absorbance at $610 \mathrm{~nm}$ (Fig. 3). To determine the range of applicability ATE or TIM when added in increasing amounts, consumes bromine and consequently, there will be a concomitant decrease in the bromine concentration. This was observed as a proportional increase in the absorbance at $610 \mathrm{~nm}$ when treated with a fixed amount of indigo carmine dye. The oxidation-bromination reaction was complete after 10 and 25 min 


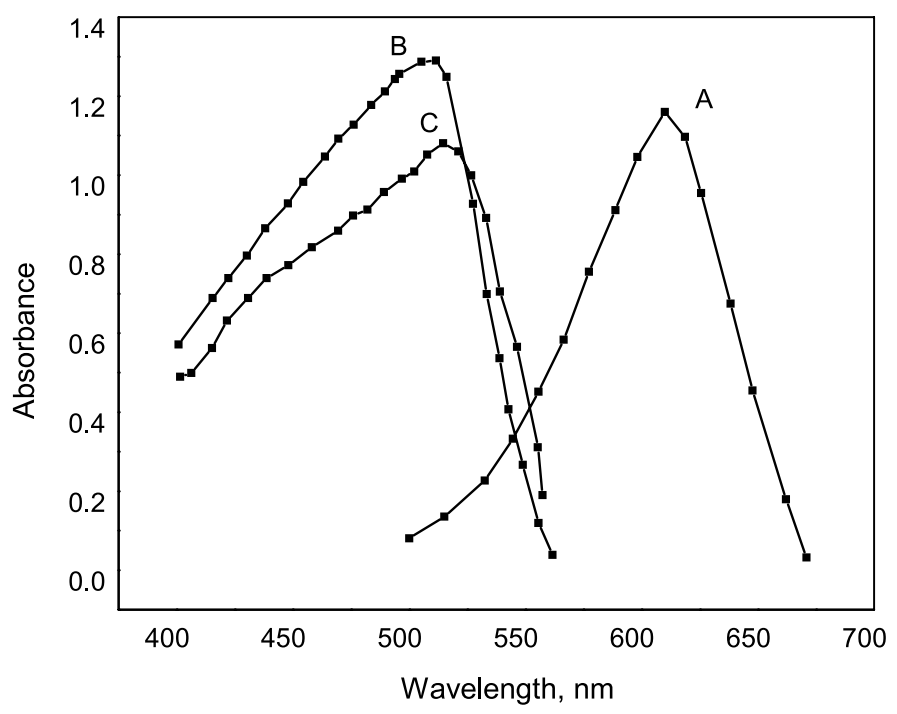

Fig. 1. Absorption spectra for the reaction products of ATE $(14 \mu \mathrm{g} / \mathrm{ml})$ with (A) IC, (B) 1,10-phenanthrloine and (C) $2,2^{\prime}$-bipyridyl.
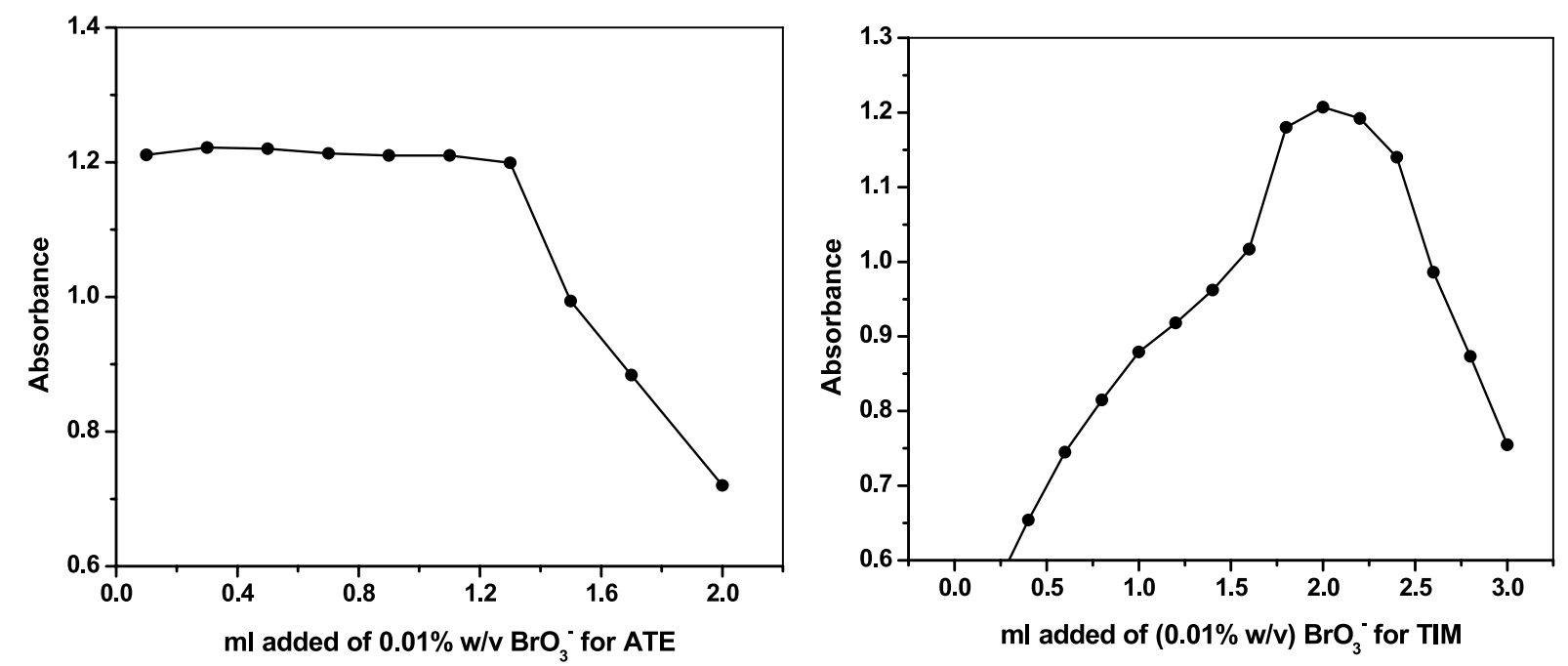

Fig. 2. Effect of added $0.01 \% \mathrm{w} / \mathrm{v} \mathrm{BrO}_{3}{ }^{-}$on development of oxidation product of ATE $(14 \mu \mathrm{g} / \mathrm{ml})$ and TIM (38 $\left.\mu \mathrm{g} / \mathrm{ml}\right)$, for method A.

for $(0.4-16.4 \mu \mathrm{g} / \mathrm{ml})$ and $(14-38 \mu \mathrm{g} / \mathrm{ml})$ range of ATE and TIM drug concentration. A contact time of 5 min was found necessary for the bleaching action. The measured absorbance of indigo carmine color was found to be stable for up to $24 \mathrm{~h}$.

\subsection{Methods B and C: Using 1,10-phenanthroline or 2,2'-bipyridyl}

The colorimetric methods are based on the complexation reaction between iron (II) and 1,10phenanthroline forming the red tris (o-phenanthroline) iron (II) chelate ion called ferroin (method B), or with 2,2'-bipyridyl forming the red colored chromogen due to the formation of iron (II)-bipy complex 

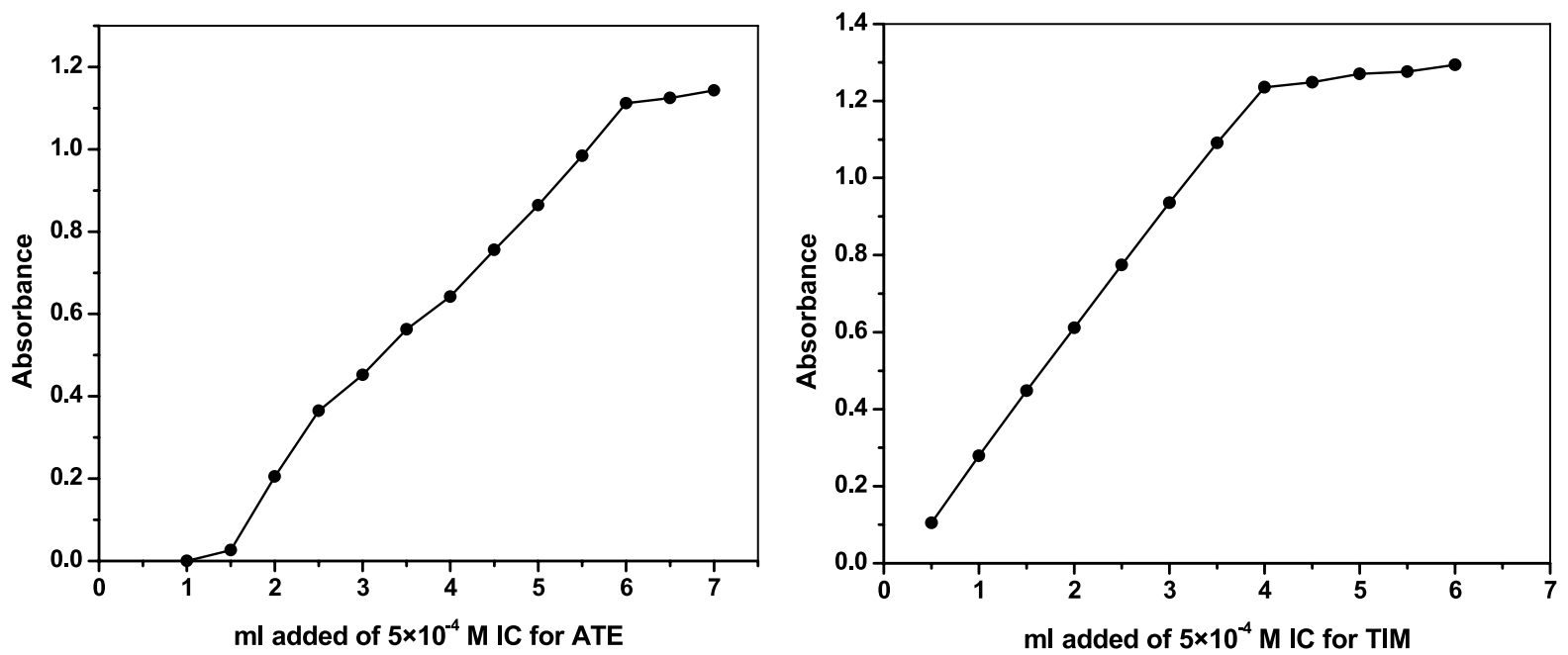

Fig. 3. Effect of added $5 \times 10^{-4} \mathrm{M}$ IC on residual bromine from oxidation of ATE $(14 \mu \mathrm{g} / \mathrm{ml})$ and TIM $(38 \mu \mathrm{g} / \mathrm{ml})$, for method A.
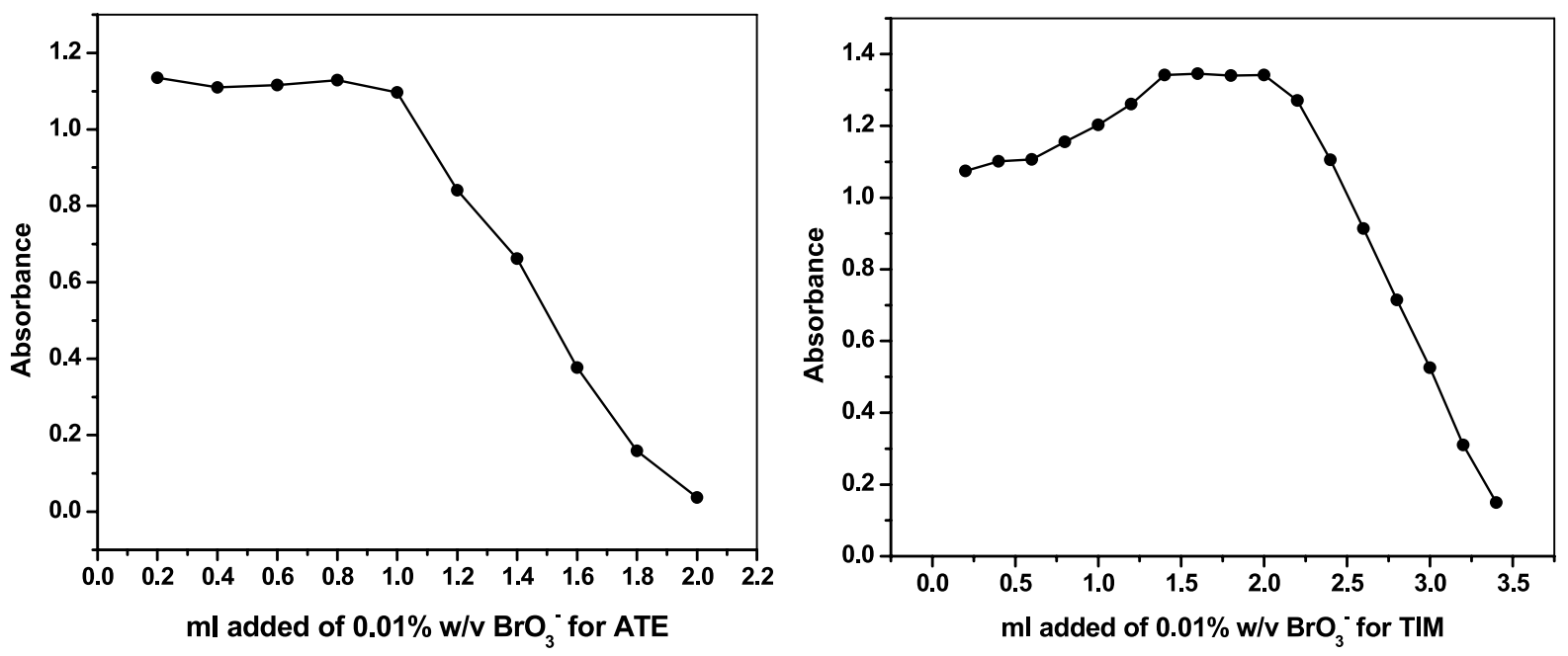

Fig. 4. Effect of added $0.01 \% \mathrm{w} / \mathrm{v} \mathrm{BrO}_{3}{ }^{-}$on development of oxidation product of ATE $(8 \mu \mathrm{g} / \mathrm{ml})$ and TIM $(32 \mu \mathrm{g} / \mathrm{ml})$, for method B.

(method C) and measuring the absorbance at 510, $522 \mathrm{~nm}$ for methods B and C, respectively (Fig. 1). Characteristic $\lambda_{\max }$ values were obtained at 510 and $522 \mathrm{~nm}$ for methods A and $\mathrm{B}$, respectively.

The optimum reaction conditions for the quantitative determination of ATE or TIM were established through a number of preliminary experiments. The results obtained show that at least 1.0 and $2.0 \mathrm{ml}$ of bromate-bromide mixture $\left(0.01 \% \mathrm{w} / \mathrm{v} \mathrm{KBrO}_{3}\right)$ is required for maximum color development in both methods B and C for ATE and TIM drugs, respectively (Fig. 4). The effects of 1,10-phenanthroline or $2,2^{\prime}$-bipyridyl were studied by measuring the absorbance of solutions containing a fixed concentration of ATE and TIM drugs and varied amounts of the reagents separately. It was observed that the maximum color intensity was obtained with 1.0; $1.4 \mathrm{ml}$ of 1,10-phenanthroline for ATE and TIM, respectively (Fig. 5) and 1.8; $1.4 \mathrm{ml}$ of 2,2'-bipyridyl for ATE and TIM, respectively (Fig. 6), after which further increase in volume resulted in no change in the absorbance for both methods. 

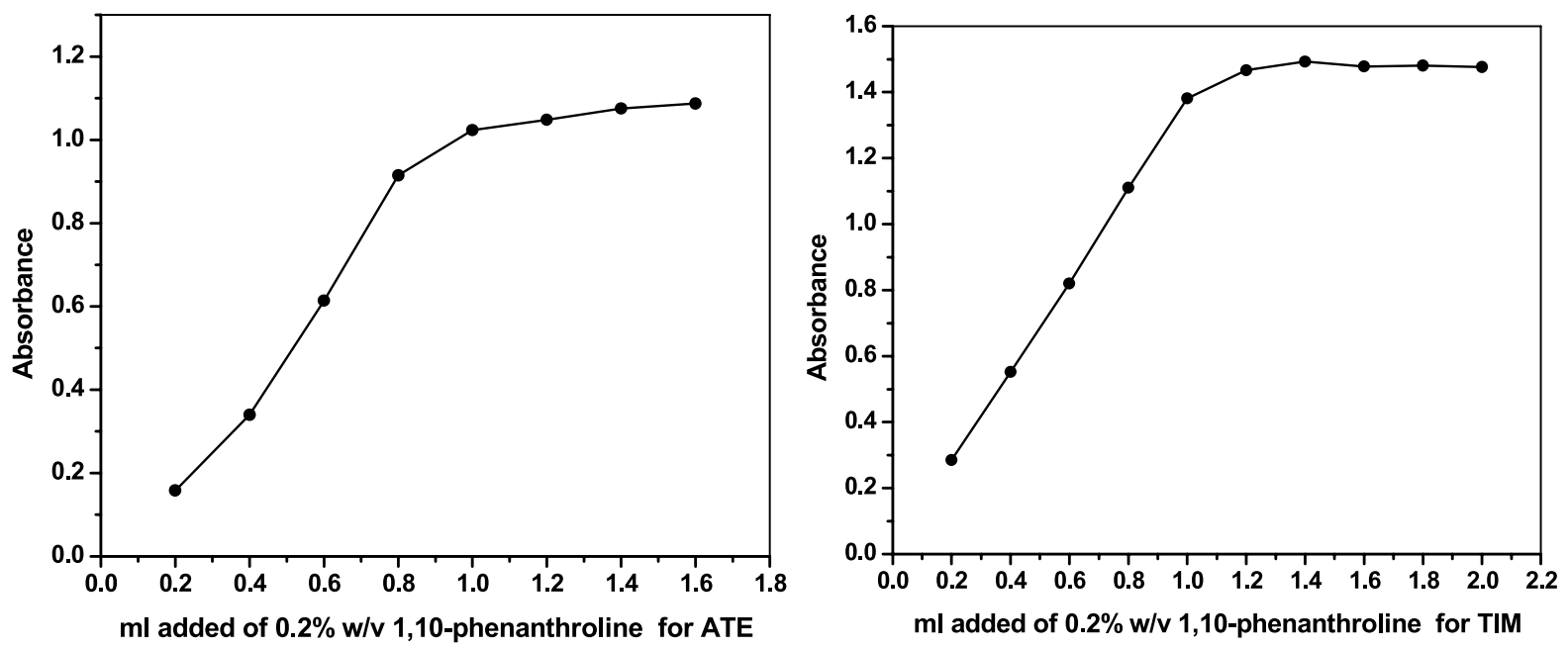

Fig. 5. Effect of added 0.2\% w/v 1,10-phenanthroline on residual Fe(II) for ATE ( $8 \mu \mathrm{g} / \mathrm{ml})$ and TIM (32 $\mu \mathrm{g} / \mathrm{ml})$, for method B.
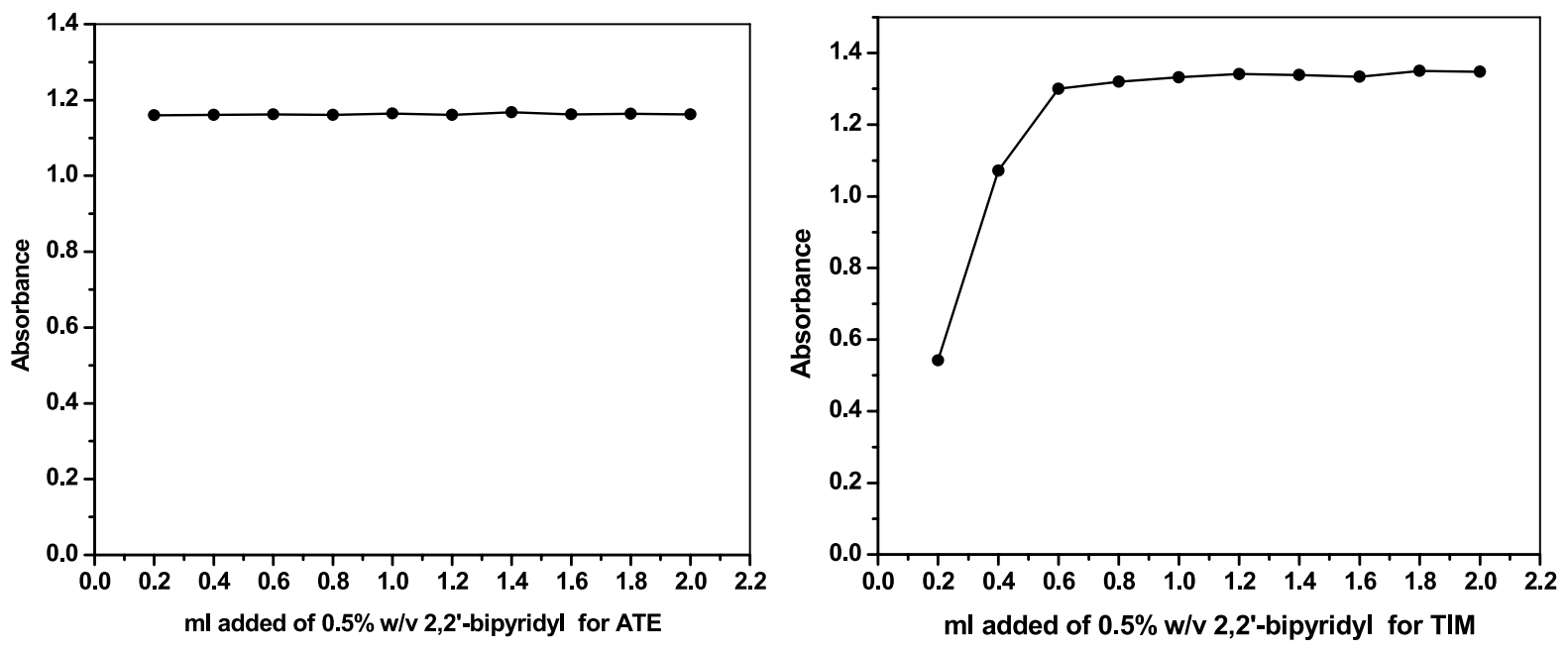

Fig. 6. Effect of added $0.5 \% \mathrm{w} / \mathrm{v} 2,2^{\prime}$-bipyridyl on residual Fe(II) for ATE (12 $\left.\mu \mathrm{g} / \mathrm{ml}\right)$ and TIM (36 $\left.\mu \mathrm{g} / \mathrm{ml}\right)$, for method C.

The ATE and TIM drugs in varying concentrations, when treated with a fixed and known concentrations of bromate-bromide mixture 1.0 and $2.0 \mathrm{ml}\left(0.01 \% \mathrm{w} / \mathrm{v} \mathrm{KBrO}_{3}\right)$ for both methods in acid medium, consumes the latter in proportionate concentrations for its oxidation and there will be an attendant decrease in the amount of the oxidant. When the decreasing concentrations of oxidant are treated with a fixed and known concentration of iron (II) $\left(0.8\right.$ and $0.7 \mathrm{ml}$ of $\left.5 \times 10^{-3} \mathrm{M}\right)$ were added for ATE and TIM, respectively (method B) and $\left(0.9\right.$ and $0.8 \mathrm{ml}$ of $\left.5 \times 10^{-3} \mathrm{M}\right)$ were added for ATE and TIM, respectively (method C) in the same acidic conditions; there will be a proportional increase in the concentration of iron (II). This is shown by the increase in the absorbance of ferroin complex and iron (II)-bipy complex formed with the residual iron (II). The absorbance measured at 510, $522 \mathrm{~nm}$ for methods B and C, respectively, was found to increase linearly with the increasing concentration of the drugs; serving as the basis for the determination of ATE and TIM drugs. 
The formation of ferroin and iron (II)-bipy complex was slow at room temperature and at low $\mathrm{pH}$ and required longer time for completion. Hence efforts were made to accelerate by carrying out the reaction at higher $\mathrm{pH}$ range (4.0-6.0). The $\mathrm{pH}$ of acidic medium employed for the redox reaction was raised by adding $1.0 \mathrm{ml}$ of $1: 1$ ammonia solution which was found to be optimum for both methods. The volume of 1:1 ammonia was not critical, since the stability and sensitivity of complexes are unaffected over a wide $\mathrm{pH}$ range. However, $1.0 \mathrm{ml}$ of $1: 1$ ammonia was used to raise the $\mathrm{pH}$ to about 4 . Under the described experimental conditions, ferroin and iron (II)-bipy complex were found to be stable for $1.0 \mathrm{~h}$.

\subsection{Validation of the proposed methods}

Linearity, detection and quantification limit. A linear correlation was found between absorbance at $\lambda_{\max }$ and the concentration ranges given in Table 1. The correlation coefficient $(r)$, the slope $(b)$ and the intercept ( $a$ ) of the regression equation $A=a+b C(A-$ absorbance, $C$ - ATE or/TIM concentration in $\mu \mathrm{g} / \mathrm{ml}$ ) are summarized in Table 1. The apparent molar absorptivity $(\varepsilon)$, Sandell's sensitivity, limit of detection (LOD) and limit of quantification (LOQ) are also given in Table 1. Results listed in Table 1, indicate high sensitivity and low background effect of the methods. Limits of detection (LOD) and limits of quantification (LOQ) were calculated as follows [31].

$$
\mathrm{LOD}=3 s / k, \quad \mathrm{LOQ}=10 s / k,
$$

whereas $s$ is the standard deviation of the absorbance of the sample and $k$ is the sensitivity, namely the slope of the related calibration graphs.

\subsection{Accuracy and precision}

To evaluate the accuracy and precision of the proposed method, solutions containing four different concentrations of the studied drugs ATE and TIM within the linearity range were analyzed, each measurement being repeated five times. Intraday precision was measured by calculating the relative standard

Table 1

Analytical parameters and optical characteristics of the proposed methods

\begin{tabular}{|c|c|c|c|c|c|c|}
\hline \multirow[t]{2}{*}{ Parameters } & \multicolumn{2}{|c|}{ Method A } & \multicolumn{2}{|c|}{ Method B } & \multicolumn{2}{|c|}{ Method C } \\
\hline & ATE & TIM & ATE & TIM & ATE & TIM \\
\hline$\lambda_{\max }(\mathrm{nm})$ & 610 & 610 & 510 & 510 & 522 & 522 \\
\hline Beer's law limit ( $\mu \mathrm{g} / \mathrm{ml})$ & $0.4-16.4$ & $14-38$ & $0.8-10.4$ & $12-32$ & $0.4-12.8$ & $14-38$ \\
\hline Molar absorptivity $(1 / \mathrm{mol} \mathrm{cm})$ & $2.09 \times 10^{4}$ & $1.38 \times 10^{4}$ & $2.97 \times 10^{4}$ & $1.89 \times 10^{4}$ & $2.42 \times 1^{4}$ & $1.37 \times 10^{4}$ \\
\hline Sandell's sensitivity $\left(\mathrm{ng} / \mathrm{cm}^{2}\right)$ & 12.7 & 31.4 & 8.96 & 22.8 & 10.98 & 31.5 \\
\hline Correlation coefficient, $r$ & 0.9998 & 0.9989 & 0.9993 & 0.9985 & 0.9989 & 0.9994 \\
\hline \multicolumn{7}{|l|}{ Linear regression equation ${ }^{*}$} \\
\hline$S_{y / x}$ & $2.01 \times 10^{-3}$ & 0.0147 & $8.43 \times 10^{-3}$ & 0.0367 & 0.0111 & 0.0121 \\
\hline Intercept, $a$ & 0.6124 & 0.0942 & 0.3750 & -0.8168 & 0.3862 & 0.4461 \\
\hline Slope, $b$ & 0.0365 & 0.0309 & 0.0786 & 0.0723 & 0.0601 & $4.79 \times 10^{-3}$ \\
\hline SD of slope, $S_{b}$ & $3.97 \times 10^{-4}$ & $1.16 \times 10^{-3}$ & $1.66 \times 10^{-3}$ & $2.90 \times 10^{-3}$ & $2.19 \times 10^{-3}$ & $9.58 \times 10^{-4}$ \\
\hline SD of intercept, $S_{a}$ & $4.61 \times 10^{-3}$ & 0.0571 & 0.0149 & 0.1427 & 0.0176 & 0.0471 \\
\hline $\operatorname{LOD}(\mu \mathrm{g} / \mathrm{ml})$ & 0.0767 & 0.2310 & 0.0621 & 0.0371 & 0.2238 & 0.2110 \\
\hline $\mathrm{LOQ}(\mu \mathrm{g} / \mathrm{ml})$ & 0.2554 & 0.7692 & 0.2049 & 0.1237 & 0.7452 & 0.7026 \\
\hline
\end{tabular}


Table 2

Evaluation of accuracy and precision of the proposed methods

\begin{tabular}{|c|c|c|c|c|c|c|}
\hline Method & Drugs & Taken $(\mu \mathrm{g} / \mathrm{ml})$ & Recovery (\%) & Precision, $\mathrm{RSD}^{\mathrm{a}}(\%)$ & Accuracy, $\operatorname{Er}^{\mathrm{b}}(\%)$ & SE \\
\hline \multirow[t]{8}{*}{$\bar{A}$} & ATE & 2 & 100.08 & 1.77 & 0.08 & $5.85 \times 10^{-3}$ \\
\hline & & 6 & 100.09 & 2.03 & 0.09 & $8.6 \times 10^{-3}$ \\
\hline & & 10 & 100.01 & 0.898 & 0.01 & $4.41 \times 10^{-3}$ \\
\hline & & 14 & 100.06 & 0.440 & 0.06 & $2.48 \times 10^{-3}$ \\
\hline & TIM & 10 & 99.68 & 1.71 & -0.32 & $2.78 \times 10^{-3}$ \\
\hline & & 18 & 100.06 & 1.91 & 0.06 & $5.94 \times 10^{-3}$ \\
\hline & & 22 & 100.1 & 0.832 & 0.1 & $3.11 \times 10^{-3}$ \\
\hline & & 34 & 100.06 & 0.396 & 0.06 & $2.19 \times 10^{-3}$ \\
\hline \multirow[t]{8}{*}{ B } & ATE & 0.8 & 100.07 & 3.41 & 0.07 & 0.0163 \\
\hline & & 4 & 100.1 & 1.18 & 0.1 & $4.28 \times 10^{-3}$ \\
\hline & & 7.2 & 100.08 & 1.16 & 0.08 & $7.85 \times 10^{-3}$ \\
\hline & & 10.4 & 100.04 & 0.767 & 0.04 & $4.37 \times 10^{-3}$ \\
\hline & TIM & 14 & 100.63 & 3.71 & 0.63 & $2.30 \times 10^{-3}$ \\
\hline & & 18 & 99.99 & 2.67 & -0.01 & $8.2 \times 10^{-3}$ \\
\hline & & 22 & 100.11 & 2.74 & 0.11 & $8.7 \times 10^{-3}$ \\
\hline & & 26 & 100.08 & 2.47 & 0.08 & 0.0112 \\
\hline \multirow[t]{8}{*}{$\mathrm{C}$} & ATE & 0.4 & 100.04 & 1.63 & 0.04 & $6.3 \times 10^{-3}$ \\
\hline & & 2 & 100.04 & 0.668 & 0.04 & $2.93 \times 10^{-3}$ \\
\hline & & 5.2 & 100.01 & 1.42 & 0.01 & $7.8 \times 10^{-3}$ \\
\hline & & 6.8 & 100.06 & 1.65 & 0.06 & 0.01 \\
\hline & TIM & 18 & 100.05 & 3.29 & 0.05 & $5.95 \times 10^{-3}$ \\
\hline & & 22 & 99.99 & 1.17 & -0.01 & $3.17 \times 10^{-3}$ \\
\hline & & 26 & 99.99 & 1.85 & -0.01 & $6.9 \times 10^{-3}$ \\
\hline & & 30 & 99.99 & 1.85 & -0.01 & $8.85 \times 10^{-3}$ \\
\hline
\end{tabular}

Notes: ${ }^{\mathrm{a}}$ Relative standard deviation for five determinations. ${ }^{\mathrm{b}} \mathrm{Er}$, Relative error.

deviation and the accuracy of the proposed method was measured by calculating relative error and found that the small values of them indicate the high accuracy and high precision of the proposed spectrophotometric method. The results of the study are compiled in Table 2 .

\subsection{Robustness}

Robustness was examined by evaluating the influence of a small variation of the methods variables including the concentration of analytical reagents and reaction time on the performance of the proposed methods. In these experiments, one parameter was changed whereas the others were kept unchanged and the recovery percentage was calculated for each time. It was found that small variations in these variables did not affect the method significantly. This was an indication of the reliability of the proposed method during its routine application for analysis of the investigated drug and so the proposed spectrophotometric methods are considered robust.

\subsection{Interference studies}

The effects of common excipients and fillers added in pharmaceutical preparations were tested for their possible interferences in the assay of ATE or/TIM. It was observed that the talc, glucose, starch, lactose, 
Table 3

Results of analysis of pharmaceutical preparations

\begin{tabular}{|c|c|c|c|c|c|c|c|}
\hline Method & Drugs & Drug formulations & $\begin{array}{c}\text { Labeled mg } \\
\text { content }\end{array}$ & $\begin{array}{c}\text { Found } \\
(\mathrm{mg})\end{array}$ & $\begin{array}{c}\text { Recovery }^{\mathrm{a}} \\
(\%)\end{array}$ & $t$ - and $F$-test & $\begin{array}{c}\text { Official } \\
\text { methods }\end{array}$ \\
\hline \multirow[t]{3}{*}{ A } & ATE & Tenormine tablet $^{\mathrm{b}}$ & 50 & 51.021 & 102.04 & $t=1.142, F=2.170$ & 100.58 \\
\hline & & Atelol tablet ${ }^{\mathrm{c}}$ & 50 & 49.788 & 99.58 & $t=0.882, F=1.114$ & 99.95 \\
\hline & TIM & Cusimolol eye drops ${ }^{\mathrm{d}}$ solution & 5 & 4.998 & 99.97 & $t=0.866, F=1.063$ & 100.15 \\
\hline \multirow[t]{3}{*}{ B } & ATE & Tenormine tablet $^{\mathrm{b}}$ & 50 & 50.115 & 100.23 & $t=0.937, F=1.087$ & 100.54 \\
\hline & & Atelol tablet ${ }^{\mathrm{c}}$ & 50 & 50.457 & 100.91 & $t=0.777, F=1.341$ & 99.98 \\
\hline & TIM & Cusimolol eye drops ${ }^{\mathrm{d}}$ solution & 5 & 5.145 & 102.90 & $t=1.736, F=1.027$ & 100.47 \\
\hline \multirow[t]{3}{*}{$\mathrm{C}$} & ATE & Tenormine tablet ${ }^{\mathrm{b}}$ & 50 & 48.953 & 97.91 & $t=0.811, F=1.227$ & 98.95 \\
\hline & & Atelol tablet ${ }^{\mathrm{c}}$ & 50 & 49.255 & 98.51 & $t=1.487, F=1.055$ & 99.11 \\
\hline & TIM & Cusimolol eye drops ${ }^{\mathrm{d}}$ solution & 5 & 4.968 & 99.36 & $t=0.888, F=0.983$ & 99.97 \\
\hline
\end{tabular}

Notes: ${ }^{\mathrm{a}}$ average of five determinations. ${ }^{\mathrm{b}}$ AstraZeneca, Egypt. ${ }^{\mathrm{c}}$ Pharco, Egypt. ${ }^{\mathrm{d}}$ Rameda, 10th of Ramadan City, Egypt. Theoretical value for $t$ - and $F$-values for five degrees of freedom and $95 \%$ confidence limits are 2.57 and 5.05, respectively.

dextrose and magnesium stearate did not interfere in the determination at the levels found in dosage forms. This is clear from the results obtained for pharmaceutical formulations, which are presented in Table 3.

\subsection{Applications}

The proposed methods were successfully applied for the determination of ATE or TIM in pharmaceutical formulations. The performance of the proposed methods was judged by calculating the Student's $t$ - and $F$-values. At 95\% confidence level, the calculated $t$ - and $F$-values did not exceed the theoretical values as evident from Table 3. Hence, it was concluded that there is no significant difference between the proposed methods and the official method [9,41]. Moreover, the spectrophotometric method for determination of ATE or TIM in pharmaceutical formulations reported in this paper are simple, fast, inexpensive, precise, accurate and it may be suitable for routine analysis.

\section{Conclusions}

The proposed methods have the advantages of simplicity and rapidity for the determination of atenolol and timolol maleate drugs in both pure and in pharmaceutical preparations. The assay methods involve less stringent control of experimental parameters such as the stability of the colored species, time of analysis and temperature independence. The reagents utilized in the proposed methods are cheaper, readily available and the procedures do not involve any tedious sample preparation. These advantages encourage the application of the proposed methods in routine quality control analysis of atenolol and timolol maleate drugs in pharmaceutical formulations.

Inter-comparison between the proposed methods $(\mathrm{A}-\mathrm{C})$ was conducted to evaluate the most sensitive one for ATE and TIM determination in bulk and in pharmaceutical preparations. The results showed that method $\mathrm{B}$, has the highest molar absorptivity value $\left(2.97 \times 10^{4}\right.$ and $1.89 \times 10^{4} \mathrm{l} / \mathrm{mol} \mathrm{cm}$ for ATE and TIM, respectively) and therefore method B was more superior. Additionally, the LOD and LOQ values for method B were lower than the other two methods. 


\section{References}

[1] Y.K. Agrawal, K. Raman, S. Rajput and S.K. Menon, Anal. Lett. 25 (1992), 1503.

[2] S.M. Al-Ghannam and F. Belal, J. AOAC Int. 85 (2002), 817.

[3] A.P. Argekar and S.G. Powar, J. Pharm. Biomed. Anal. 21 (2000), 1137.

[4] R. Arias, R.M. Jimenez, R.M. Alonso, M. Telez, I. Arrieta, P. Flores and E. Ortiz-Lastra, J. Chromatogr. A 916 (2001), 297.

[5] A. Arranz, I. Dolara, S. Fernandez De Betofio, J. Maria Moreda, A. Cid and J.F. Arranz, Anal. Chim. Acta 389 (1999), 225.

[6] M.M. Ayad, A. Shalaby, H.E. Abdellatef and M.M. Hosny, Anal. Bioanal. Chem. 375 (2003), 556.

[7] K. Basavaiah, U. Chandrashekar and P. Nagegowda, Indian J. Chem. Techol. 11 (2004), 769.

[8] D. Bonazzi, R. Gotti, V. Andrisano and V. Cavrini, Farmaco 51 (1996), 733.

[9] British Pharmacopoeia, Vol. I, Her Majesty's Stationery Office, London, 1988, p. 49.

[10] British Pharmacopoeia, Her Majesty's Stationery Office, London, 1993, pp. 641, 692.

[11] R. Cavalli, A. Serafino, M.E. Carlotti and M.R. Gasco, J. Pharm. Sci. 83 (1994), 609.

[12] P. Chiap, P. Hubert, B. Boulanger and J. Crommena, Anal. Chim. Acta 391 (1999), 227.

[13] A. El-Gindy, S. Sallam and R.A. Abdel-Salam, J. Sep. Sci. 31 (2008), 677.

[14] A.A. Elshanawane, S.M. Mostafa and M.S. Elgawish, J. AOAC Int. 92 (2009), 404.

[15] N. Erk, J. Pharm. Biomed. Anal. 28 (2002), 391.

[16] J.A. Franciosa, E.D. Freis and J. Conway, Circulation 48 (1973), 118.

[17] W.H. Frishman, N. Eng. J. Med. 305 (1981), 500.

[18] G. Garg, S. Saraf and S. Saraf, Indian J. Pharm. Educt. Res. 42 (2008), 74.

[19] A. Gölcü, J. Anal. Chem. 63 (2008), 538.

[20] R.N. Goyal, V.K. Gupta, M. Oyama and N. Bachheti, Electrochem. Commun. 8 (2006), 65.

[21] R.N. Goyal and S.P. Singh, Talanta 69 (2006), 932.

[22] I.I. Hamdan and H. Qurani, J. Liq. Chromatogr. Related Technol. 32 (2009), 449.

[23] J. Huang, J. Sun, X. Zhou and T. You, Anal. Sci. 23 (2007), 183.

[24] I.U. Khan, N. Yaqoob and M. Ahmad, Chem. Anal. 50 (2005), 951.

[25] K. Kubota, H. Nakamura, E. Koyama, T. Yamada, K. Kikuchi and T. Ishizaki, J. Chromatogr. B 533 (1990), 255.

[26] S.P. Kulkarni and P.D. Amin, J. Pharm. Biomed. Anal. 23 (2003), 983.

[27] B. Kumar, R. Patel and A. Bhandari, Asian J. Chem. 18 (2006), 3049.

[28] D. Li, J. Du and J. Lu, Microchim. Acta 161 (2008), 169.

[29] M.I. Maguregui, R.M. Alonso and R.M. Jimenez, J. Liq. Chromatogr. Related Technol. 20 (1997), 3377.

[30] R.D. Marini, P. Chiap, B. Boulanger, S. Rudaz, E. Rozet, J. Crommen and P. Hubert, Talanta 68 (2006), 1166.

[31] J.C. Miller and J.N. Miller, Significance Tests in Statistics for Analytical Chemistry, 3rd edn, Hardwood, Chichester, 1993.

[32] Ministry of Health and Family Welfare, Government of India, The Indian Pharmacopoeia, 4th edn, Controller of Publications, New Delhi, 1996.

[33] P. Norouzi, M.R. Ganjali, A. Sepehri and M. Ghorbani, Sens. Actuators B 110 (2005), 239.

[34] T.V. Olah, J.D. Gilbert and A. Barrish, J. Pharm. Biomed. Anal. 11 (1993), 157.

[35] J.E.F. Reynolds (ed.), Martindale: Extra Pharmacopoeia, 28th edn, Pharmaceutical Press, London, 1982.

[36] E.R. Sartori, R.A. Medeiros, R.C. Rocha-Filho and O. Fatibello-Filho, Talanta 81 (2010), 1418.

[37] A. Shafaati and B.J. Clark, J. Pharm. Biomed. Anal. 14 (1996), 1547.

[38] A.K. Singh, E.R.M. Kedor-Hackmann and M.I.R. Santoro, J. AOAC Int. 84 (2001), 1724.

[39] N. Sultana, M.S. Arayne and B. Iftikhar, J. Chin. Chem. Soc. 55 (2008), 1022.

[40] The Norwegian Multicentre Study Group, N. Eng. J. Med. 304 (1981), 801.

[41] The United States Pharmacopoeia, 24th rev. edn, The National Formulary, United States Pharmacopeial Convention, 2000, p. 638.

[42] A. Thomas, M. Patankar, K.R. Deshmukh, L. Kothapalli, S. Jangam, P.R. Patankar, S.A. Kandgaonkar and A.D. Deshpande, Asian J. Chem. 19 (2007), 3721.

[43] M.H. Türkdemir, G. Erdögdu, T. Aydemir, A.A. Karagözler and A.E. Karagözler, J. Anal. Chem. 56 (2001), 1047.

[44] P. Umapathi, Int. J. Pharm. 108 (1994), 11.

[45] L. Vlase, S. Leucuta and S. Imre, Rev. Chim. 58 (2007), 3. 


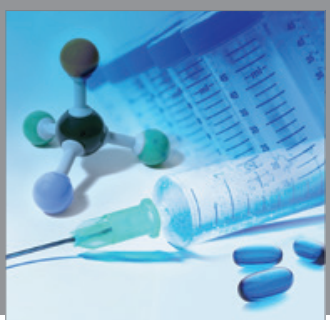

International Journal of

Medicinal Chemistry

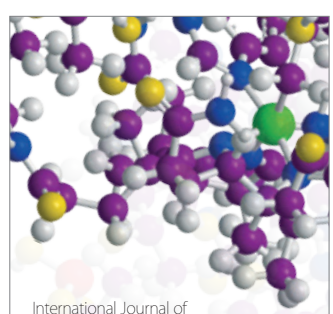

Carbohydrate Chemistry

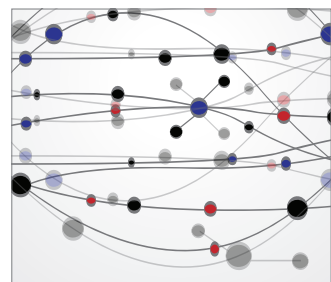

The Scientific World Journal
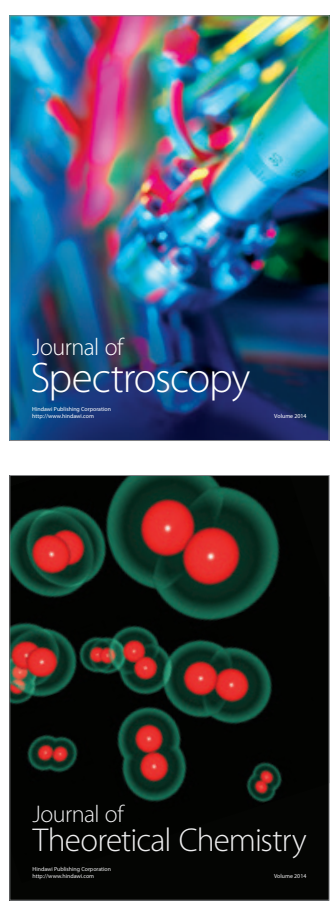
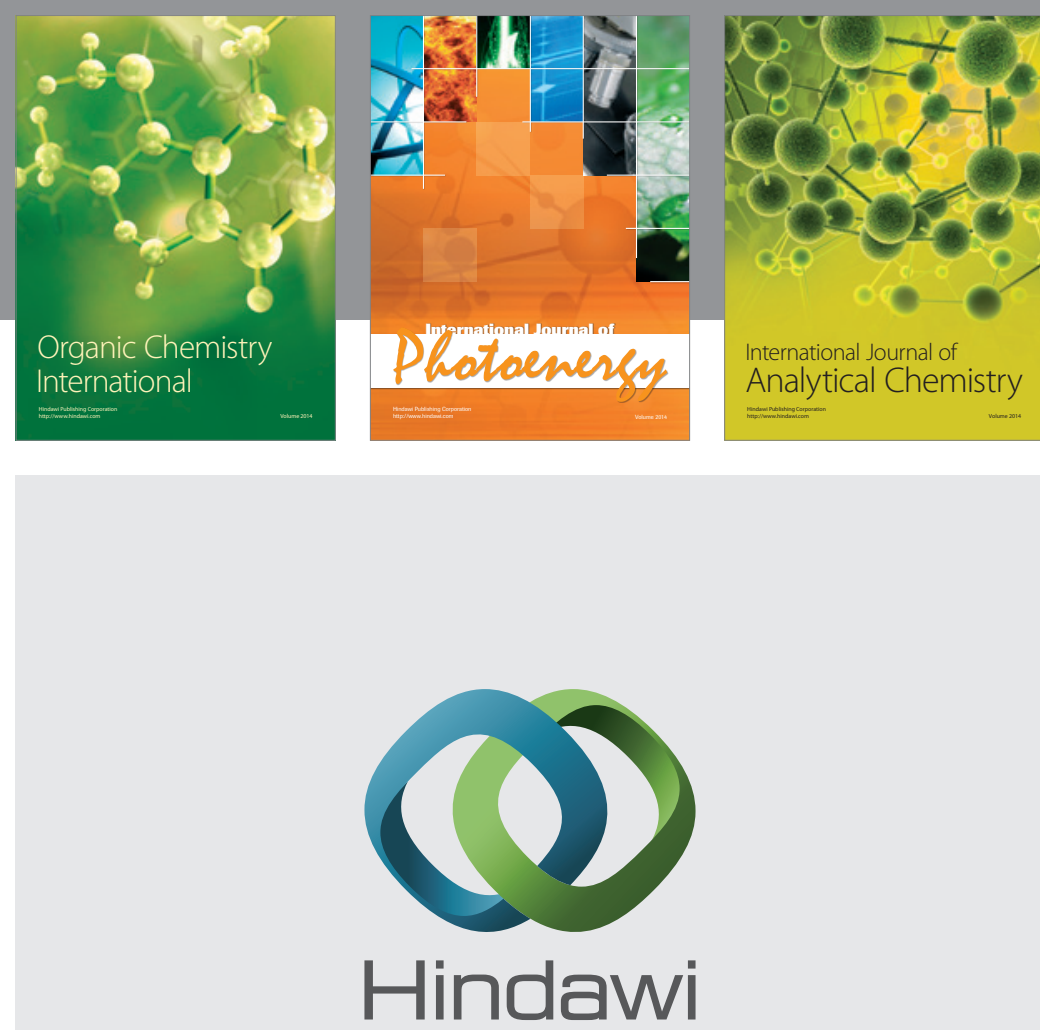

Submit your manuscripts at

http://www.hindawi.com
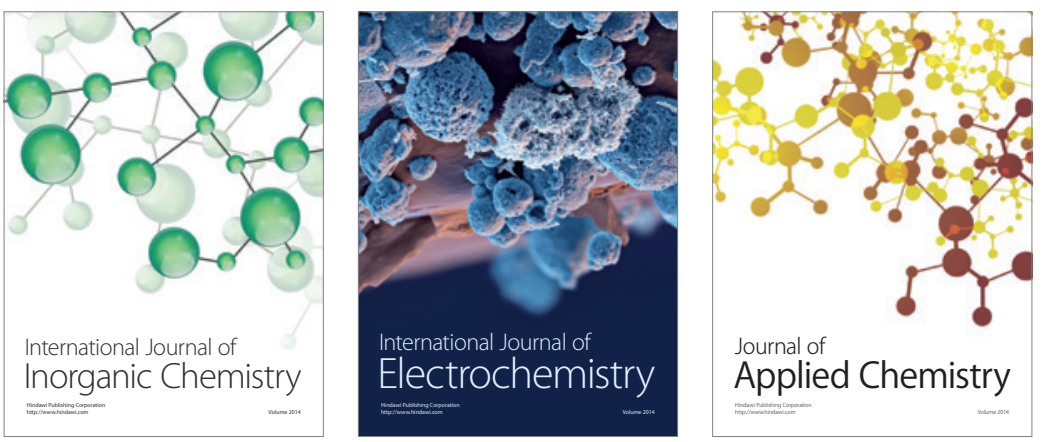

Journal of

Applied Chemistry
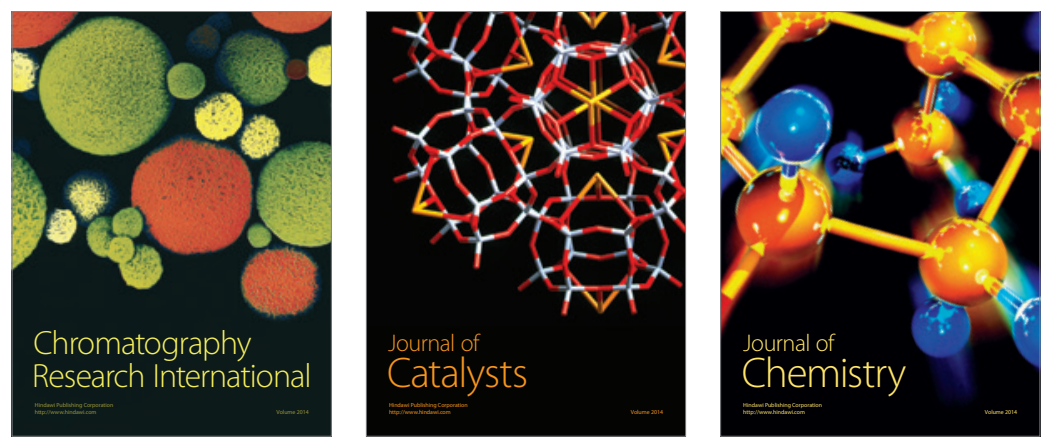
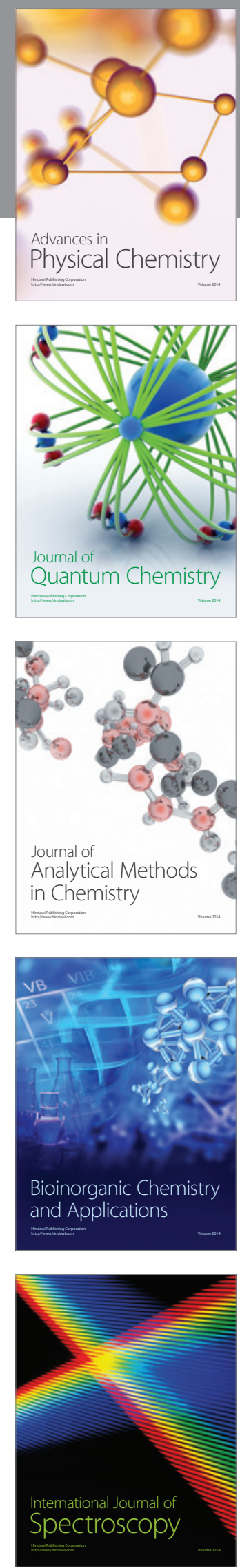